\title{
Hybrid Solar Cells from Water-Soluble Polymers
}

\author{
James T. McLeskey Jr. and Qiquan Qiao \\ Department of Mechanical Engineering, Energy Conversion Systems Laboratory, Virginia Commonwealth University, \\ Richmond, VA 23284, USA
}

Received 16 February 2006; Accepted 23 March 2006

We report on the use of a water-soluble, light-absorbing polythiophene polymer to fabricate novel photovoltaic devices. The polymer is a water-soluble thiophene known as sodium poly[2-(3-thienyl)-ethoxy-4-butylsulfonate] or PTEBS. The intention is to take advantage of the properties of conjugated polymers (flexible, tunable, and easy to process) and incorporate the additional benefits of water solubility (easily controlled evaporation rates and environmentally friendly). The PTEBS polythiophene has shown significant photovoltaic response and has been found to be effective for making solar cells. To date, solar cells in three different configurations have been produced: titanium dioxide $\left(\mathrm{TiO}_{2}\right)$ bilayer cells, $\mathrm{TiO}_{2}$ bulk heterojunction solar cells, and carbon nanotubes (CNTs) in bulk heterojunctions. The best performance thus far has been achieved with $\mathrm{TiO}_{2}$ bilayer devices. These devices have an open circuit voltage $\left(V_{\text {oc }}\right)$ of $0.84 \mathrm{~V}$, a short circuit current $\left(J_{\mathrm{sc}}\right)$ of $0.15 \mathrm{~mA} / \mathrm{cm}^{2}$, a fill factor $(f f)$ of 0.91 , and an efficiency $(\eta)$ of $0.15 \%$.

Copyright (C) 2006 J. T. McLeskey Jr. and Q. Qiao. This is an open access article distributed under the Creative Commons Attribution License, which permits unrestricted use, distribution, and reproduction in any medium, provided the original work is properly cited.

\section{INTRODUCTION}

Photovoltaics made using polymer-based semiconductors have become the subject of intense research in recent years [1] because they offer a number of potential advantages when compared to more traditional materials such as silicon. These organic solar cells can be fabricated using inexpensive liquidbased processing $[2,3]$ leading to potentially lower costs per Watt. In addition, by modifying the chemical structure of the polymers, the band gap and ionization potential can be tuned to absorb the desired parts of the solar spectrum [4]. They are also generally flexible which offers the possibility of integration into building materials and appliances [5].

Organic polymer solar cells are generally fabricated in one of several configurations. Homojunctions consist of a single homogeneous layer between two electrodes. To date, these devices have been inefficient. However, it has been found that at the interface between two materials with different electron affinities, charge transfer is energetically favorable [6] and this discovery has led to the development of heterojunctions.

In a bilayer (or planar) heterojunction, an inorganic semiconductor (such as porous nanocrystalline $\mathrm{TiO}_{2}$ [7] or $\mathrm{ZnO}[8])$ is deposited onto a transparent electrode $\left(\mathrm{SnO}_{2}\right)$. The polymer is then spin-coated or drop cast on top of the semiconductor (Figure 1). In a bulk (or dispersed) heterojunction, nanocrystals are blended into the polymer to create a heterogeneous composite with a high interface surface area (Figure 2). Typically the nanocrystal has a higher electron affinity and serves as the acceptor for the electron. Electron acceptors have been fabricated from a number of materials including $\mathrm{TiO}_{2}[9]$, CdSe [4, 6], CdS [10], carbon fullerenes [11], and carbon nanotubes [12,13]. Bulk heterojunction solar cells with conversion efficiencies over $5 \%$ have been reported [1].

In the work described in this paper, we utilize the unique properties of a water-soluble, light-absorbing polythiophene polymer to fabricate novel photovoltaic devices. The idea is to take advantage of the properties of conjugated polymers (flexible, tunable, and easy to process) and incorporate the additional benefits of water solubility to build high efficiency solar cells using low cost materials and processing methods.

The benefits of using water as the solvent are numerous. Solvent evaporation rates have been shown to have a strong influence on film morphology and device performance. $[14,15]$ and the evaporation of water can be carefully controlled using heat. Because water is a part of the fabrication process, devices made from this polymer can show improved stability under atmospheric conditions. Acidic solutions of the water-soluble polymer develop a new absorption band in the near-IR and films made from the self-acid form of the polymer show the same optical characteristics [16]. 


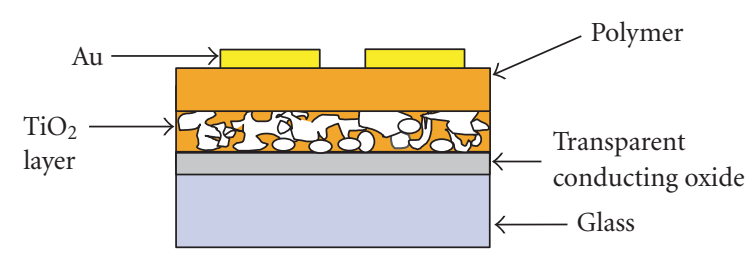

FIGURE 1: Bilayer heterojunction solar cell.

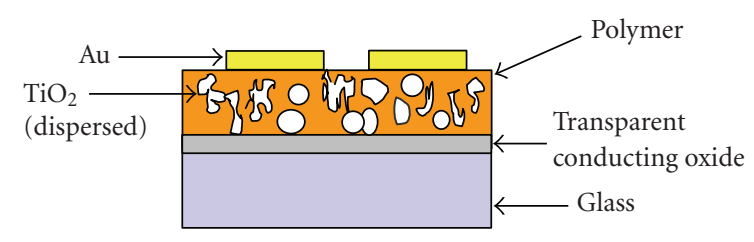

FIGURE 2: Bulk heterojunction solar cell.

In addition to improved light harvesting from single junction cell, this increased absorption also opens the possibility for building tandem junction cells with layers made using both acidic and basic solutions in order to match a greater portion of the solar spectrum. Obviously, water is environmentally friendly and nontoxic.

\section{PTEBS POLYMER}

The polymer utilized in this research is a water-soluble thiophene known as sodium poly[2-(3-thienyl)-ethoxy-4butylsulfonate] or PTEBS. The PTEBS was purchased from American Dye Source [17]. Tran-Van et al. [16] reported that the synthesis of the polymer occurs in 3 primary steps. First, thienyl ethanol in toluene is mixed with sodium hydride and butanesultone to form the TEBS monomer ((3thienyl)ethoxybutanesulfonate). Tetrabutylammonium (3thienyl)ethoxybutanesulfonate (TEBSTBA) is then synthesized from the TEBS by adding tetrabutylammonium hydroxide, extracting with $\mathrm{CH}_{2} \mathrm{Cl}_{2}$ and drying on $\mathrm{MgSO}_{4}$. Finally, the PTEBS polymer is synthesized from the TEBSTBA using $\mathrm{FeCl}_{3}$ as an oxidant.

Although the solar spectrum is concentrated in the band from $400 \mathrm{~nm}$ to $700 \mathrm{~nm}$, most polymers show poor light absorption in the red and infrared regions [5]. This poor absorption reduces the potential efficiency of polymer-based solar cells. It has been shown that the absorption spectrum of the PTEBS polymer can be tuned by acid doping [18]. In the experiment, two solutions with 1\% PTEBSNa by weight were prepared: a basic solution $(\mathrm{pH}>7)$ and an acidic solution $(\mathrm{pH} \sim 1)$. The basic solution was made by adding a few drops of ammonium hydroxide to the 1\% PTEBS solution dissolved in deionized water. This basic solution is orange in color. For acidic solutions, PTEBSNa was dissolved in a 3 : 1 volume ratio solution of hydrochloric acid $(\mathrm{HCl}, 35 \%)$ and deionized (DI) water. The acidic solution was green in color. The absorption of the solutions was measured using a Lambda $40 \mathrm{UV}$-Vis spectrometer and the absorption spectra are shown in Figure 3.

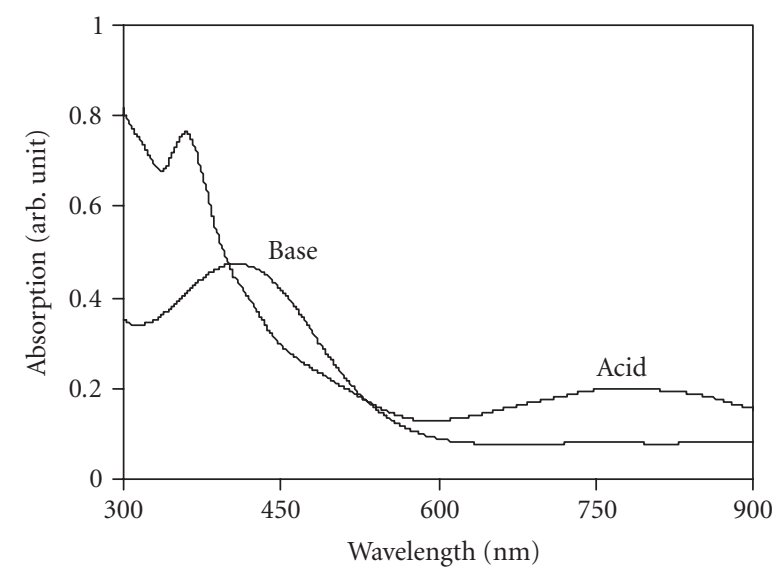

Figure 3: Absorption spectrum of PTEBS polymer.

Thin films of PTEBS made from $\mathrm{HCl}$ and basic solutions were also investigated. The films have an appearance similar to their respective solutions (green and orange) and the absorption spectra of the films are similar to those of the solutions. In addition to the red-near infrared (IR) absorption band reported by Tran-Van et al. [16], a new absorption band in the ultraviolet after doping with $\mathrm{HCl}$ was observed.

Two mechanisms have been proposed for the change in absorption due to the addition of an acid. After acidification, the proton salt (acid form) of poly[2-(3-thienyl)ethoxy-4-butylsulfonate] acid [PTEBSH] was obtained via ion-exchange treatment by adding hydrochloric acid into a PTEBSNa solution. In the acidification process, an equilibrium reaction occurs between sodium salt and proton salt of PTEBS, as depicted in Scheme 1 [17].

In addition to the cation exchange between the sodium and hydrogen shown in the scheme, self-doping has also been proposed to occur in the acidification process $[19,20]$. Following the removal of the cation, the counterion binds covalently to the polymer backbone chain simultaneously with electron loss in the doping and oxidation, which is different from the normal doping mechanism by the incorporation of a new anion $[19,20]$. The self-doped polymers showed an increased conductivity and changes in the optical and infrared absorption after acidification [16]. These new absorption bands may lead to increased device efficiency.

Figure 4 shows the electrochemical characterization of a cast film of PTEBS deposited on an FTO substrate. FTO glass was the working electrode. As is shown in Figure 4, the oxidation onset occurs at $\sim+0.6 \mathrm{~V}$ versus saturated calomel electrode (SCE). The HOMO level of PTEBS can be estimated at the onset point. Typically, an adjustment factor of 4.4 to $4.7 \mathrm{eV}$ is used in converting the energy values versus SCE into energy values versus vacuum. Therefore, the HOMO level is estimated to be between $-5.0 \mathrm{eV}$ and $-5.3 \mathrm{eV}$. The energy band gap of the high molecular weight of PTEBS from the absorption onset $(560 \mathrm{~nm})$, that is, around $2.2 \mathrm{eV}$, which results in a LUMO level between $-2.8 \mathrm{eV}$ and $-3.1 \mathrm{eV}$. Qiao and McLeskey [7] previously reported that 


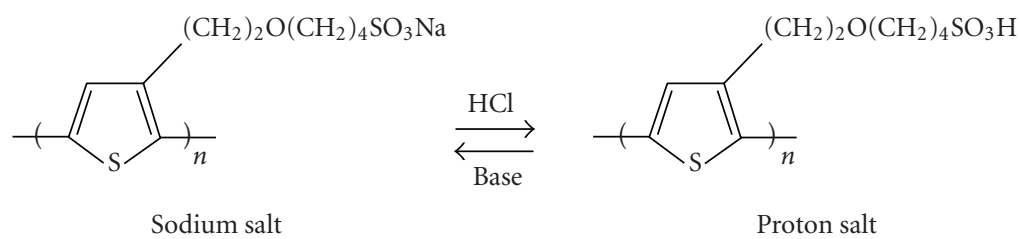

Scheme 1

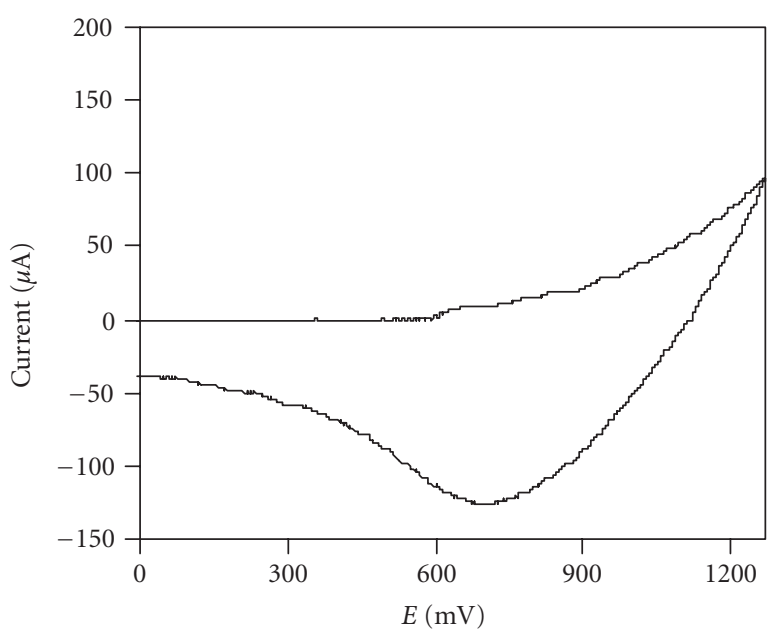

FIgURE 4: Cyclic voltammogram of PTEBS polymer.

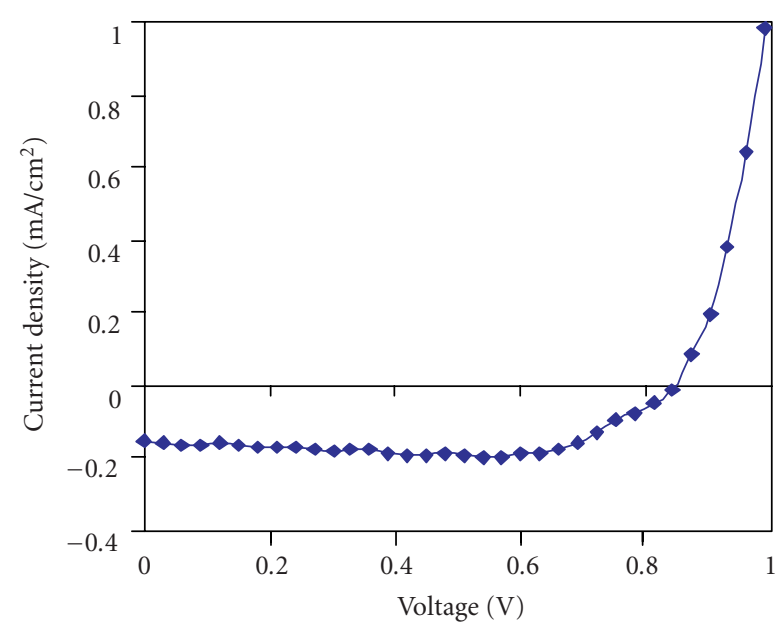

Figure 5: J-V curve for PTEBS bilayer solar cell.
HOMO of low MW PTEBS is approximately $-4.7 \mathrm{eV} \sim$ $-5.1 \mathrm{eV}$ and its LUMO is about $-2.7 \mathrm{eV} \sim-3.1 \mathrm{eV}$, utilizing the results of cyclic voltamperometry measured by Tran-Van et al. [16].

\section{SOLAR CELL CONFIGURATIONS}

To date, solar cells in four different configurations have been produced using the PTEBS polymer.

\subsection{Titanium dioxide $\left(\mathrm{TiO}_{2}\right)$ bilayer cells}

In these simple devices [7], a layer of $\mathrm{TiO}_{2}$ is deposited onto fluorinated tin oxide coated glass. The $\mathrm{TiO}_{2}$ is sintered and the PTEBS polymer is then drop cast on top of the resulting nanocrystalline $\mathrm{TiO}_{2}$ layer. The PTEBS acts as the electron donor and the $\mathrm{TiO}_{2}$ acts as the electron acceptor.

The device configuration was Glass/FTO/TiO $2 / \mathrm{PTEBS} /$ $\mathrm{Au}$ and is shown in Figure 1. Fluorinated tin oxide (FTO) coated glass squares $(2.5 \mathrm{~cm} \times 2.5 \mathrm{~cm})$ were used as substrates. The FTO coated glass has a resistance of 12.5-14.5 ohms/square and a layer thickness of $400 \mathrm{~nm}$. The substrates were cleaned in ultrasonic baths with acetone, 2-propanol and then deionized water for 5 minutes each.

To make the $\mathrm{TiO}_{2}$ films, an anatase $\mathrm{TiO}_{2}$ powder was first suspended in deionized water to a concentration of $30 \%$ by weight and then sonicated for three hours. The $\mathrm{TiO}_{2}$ films were made by spin coating onto the conductive FTO layer of the substrates. The $\mathrm{TiO}_{2}$ films were then sintered at $500{ }^{\circ} \mathrm{C}$ for one hour and an Ambios XP-1 surface profiler was used to measure the exact film thickness [21].

Three hundred $\mathrm{ml}$ of PTEBS solution was evenly drop cast on top of the $\mathrm{TiO}_{2}$ layer and then dried on a heating plate at $50{ }^{\circ} \mathrm{C}$. Any excess solution was removed with a pipet during the drying process. Finally, a mask was applied to the sample to define a $2 \mathrm{~mm} \times 5 \mathrm{~mm}$ device area and $50 \mathrm{~nm}$ of gold was sputter coated onto the polymer to serve as the electrode at a vacuum of $200 \mathrm{~m}$ Torr.

The devices were tested in the dark and under AM1.5 illumination with an intensity of approximately $80 \mathrm{~mW} / \mathrm{cm}^{2}$ through the FTO electrode. The current density-voltage (JV) curve was measured using a Keithley 236 source generator by varying the voltage from $0 \mathrm{~V}$ to $1.5 \mathrm{~V}$ in $0.03 \mathrm{~V}$ steps across the FTO and gold electrodes (Figure 5). Samples with thicknesses in the range of $180 \mathrm{~nm} \sim 8.08 \mu \mathrm{m}$ have been fabricated to investigate the dependence of the efficiency on the $\mathrm{TiO}_{2}$ thickness. There is an increase in the energy conversion efficiency $(\eta)$ with the thickness, reaching a maximum value of $0.15 \%$ at about $4.17 \mu \mathrm{m}$. Above this value, efficiency decreases as the thickness continues to increase.

Bilayer devices have been fabricated with an open circuit voltage $V_{\mathrm{oc}}=0.84 \mathrm{~V}$, a short circuit current $J_{\mathrm{sc}}=0.15 \mathrm{~mA} / \mathrm{cm}^{2}$, a fill factor $f f=0.91$, and efficiency $\eta=0.15 \%$ under approximately $80 \mathrm{~mW} / \mathrm{cm}^{2}$ AM 1.5 illumination. Although the exact origin of the open circuit voltage in this type of device structure is not fully understood, it has been demonstrated 
[22] that $V_{\text {oc }}$ can be estimated by the difference of the work functions of the electrodes. This same estimate can be applied here. As seen in Figure 6, the difference between the work functions of gold (5.2 eV) [23] and of FTO (4.4 eV) [24] matches the measured open circuit voltage $\left(V_{\mathrm{OC}}=0.8 \mathrm{~V}\right)$. In this particular case, however, the work function of the gold contact is very close to the HOMO level of the polymer $(5.1 \mathrm{eV})$ and the work function of the FTO is close to the conduction band energy of the $\mathrm{TiO}_{2}(4.2 \mathrm{eV})$ [2]. This makes it difficult to ascertain the influence of the polymer and the $\mathrm{TiO}_{2}$ on the $V_{\text {oc }}$.

\subsection{Titanium dioxide bulk heterojunction solar cells}

Water solubility is compatible with a number of different processing techniques. For example, titania $\left(\mathrm{TiO}_{2}\right)$ is generally deposited from an aqueous suspension. This leads to the elegant solution of creating a bulk heterojunction [2] by depositing the nanoparticles $\left(\mathrm{TiO}_{2}\right)$ and the polymer in a single step by spray coating or screen printing.

The devices are fabricated on the same substrates as the bilayer devices. The PTEBS was dissolved in DI water at a concentration of $15 \mathrm{mg} / \mathrm{ml}$ and a few drops of ammonium hydroxide were added for better dissolution. The solution was stirred for three days on a $40^{\circ} \mathrm{C}$ heating plate to increase the solubility of PTEBS. The solution turns orange when PTEBS is satisfactorily dissolved. Composite solution samples were then prepared by adding $\mathrm{TiO}_{2}$ to the PTEBS solutions. The concentration of the $\mathrm{TiO}_{2}$ relative to the PTEBS was $100 \mathrm{wt} \%$ ( 1 PTEBS: $1 \mathrm{TiO}_{2}$ ). The solutions were sonicated for 4 hours to disperse the $\mathrm{TiO}_{2}$ powder and prevent the separated powder from aggregating again. A $300 \mu \mathrm{l}$ solution of $\mathrm{TiO}_{2} /$ PTEBS was drop cast on FTO substrates until the whole surface was covered. Subsequently, the substrate with the solution on the surface was moved onto a $150{ }^{\circ} \mathrm{C}$ heating plate and dried. Both the solution and film samples were prepared in air.

$\mathrm{TiO}_{2}$ bulk heterojunction devices have been fabricated with $V_{\mathrm{oc}}=0.72 \mathrm{~V}, J_{\mathrm{sc}}=0.22 \mathrm{~mA} / \mathrm{cm}^{2}, f f=0.29$, and $\eta=$ $0.015 \%$ [25] under approximately $300 \mathrm{~mW} / \mathrm{cm}^{2}$ white light illumination. The open circuit voltage can be explained in the same manner as for the bilayer structure. The low short circuit current and efficiency is likely because charge transfer to the electrodes is inhibited due to the limited paths for the separated electrons in the composite. This is because the $\mathrm{TiO}_{2}$ nanocrystals are not always in physical contact with each other [26], leading to discontinuous paths for electrons. Recombination occurs when the electrons leave the $\mathrm{TiO}_{2}$ and re-enter the polymer [10].

Improved charge transport may be possible through the use of aligned $\mathrm{TiO}_{2}$ nanorods or needles [6]. Previous experiments [27] have shown that it is possible to use electric or magnetic fields to pattern the $\mathrm{TiO}_{2}$. Aligned nanorods would result in continuous paths for the generated electrons to travel to the electrode.

To better understand the charge separation and transfer in the composites, photoluminescence (PL) spectroscopy was performed. It has been shown $[10,28]$ that the concentration of the nanocrystals affects the PL spectra and intensity. In

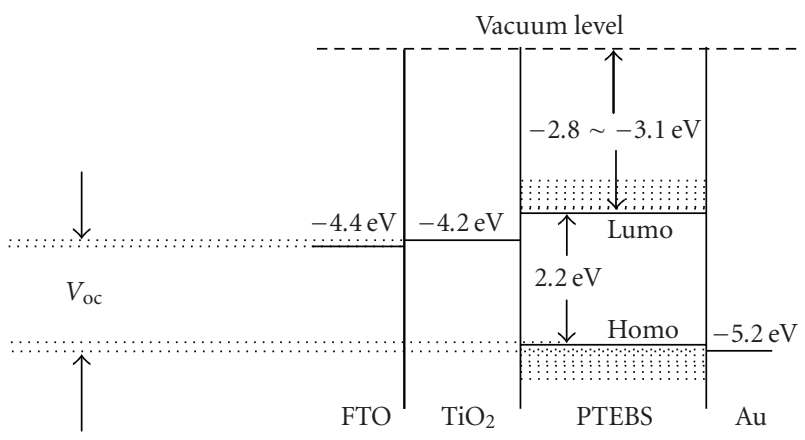

FIgURe 6: Energy level diagram for PTEBS/ $\mathrm{TiO}_{2}$ solar cell.

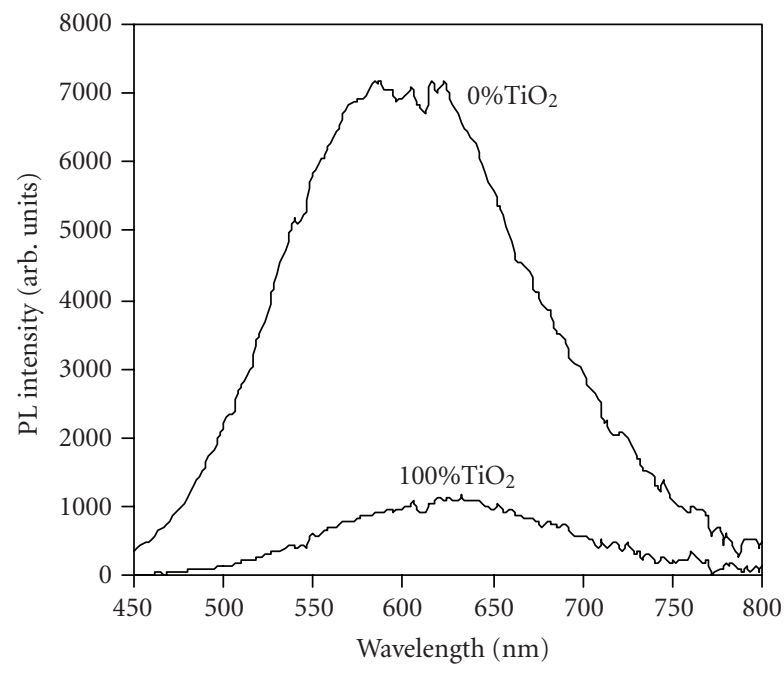

FIgure 7: Photoluminescence of PTEBS/TiO ${ }_{2}$ composite.

addition, Salafsky [26] reported that the degree of the photoluminescent quenching is an indication of how well the nanocrystals are mixed in the polymer and the quality of polymer-nanocrystal interface.

The PL intensity for the $\mathrm{PTEBS} / \mathrm{TiO}_{2}$ composite was measured using a $50 \mathrm{~mW}, 325 \mathrm{~nm}$ HeCd laser with spot diameter of $4 \mathrm{~mm}$. Figure 7 shows the PL of two different film samples. The first film was prepared from pure PTEBS and the second from a composite of $100 \% \mathrm{TiO}_{2}$ by weight of PTEBS. The laser was directly incident on the films and the PL was collected from the same side. To simplify the comparison, both films were approximately $10 \mu \mathrm{m}$ thick, which is thick enough to absorb nearly all of the light from the excitation laser. As shown in Figure 7, there is a significant quenching of the fluorescence in the composite as compared to the pure PTEBS. The PL is quenched by a factor of about 7 with the $\mathrm{TiO}_{2}$. Although the polymer is a good hole conductor, the likelihood of recombination in pure polymer films is high because these materials suffer from low electron mobility and short exciton diffusion lengths [9]. In the polymer- $\mathrm{TiO}_{2}$ bulk structures, PL quenching implies that the excitons dissociate and separate successfully at the interface of PTEBS (donor) 


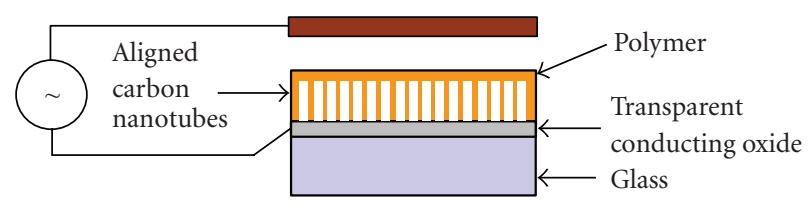

Figure 8: Alignment of carbon nanotubes by an electric field.

and $\mathrm{TiO}_{2}$ (acceptor). The polymer phase in the composites is continuous and forms favorable paths for holes throughout the film.

\subsection{Carbon nanotubes (CNTs) in bulk heterojunctions}

Blending of CNTs into a polymer solar cell as the electron acceptor has been reported to improve exciton dissociation due to the built-in potential [29]. Our group has advanced this concept by attempting to use an electric field to align the CNTs [30]. Alignment enhances charge transport in the solar cell [6] by providing a direct path for the carriers (electrons) to reach the electrode. The carbon nanotubes used in the heterojunctions are single-wall CarboLex AP-grade with a diameter of 1.2-1.5 nm from Sigma-Aldrich [31]. The bulk length of the nanotubes is given as $20 \mu \mathrm{m}$ but the individual length is not reported [31]. The polymer was dissolved in deionized water to a concentration of $3 \%$. The nanotubes were added to $1 \%$ by weight. The solution was slightly basic. The polymer/nanotube solution was drop cast onto the same FTO coated glass substrates used in the other experiments. An electric field was used in an effort to align the nanotubes during curing (Figure 8) [32] and finally, a $250 \mathrm{~nm}$ thick aluminum rear contact was applied by horizontal sputtering. The rear contact was approximately $1 \mathrm{~cm}^{2}$ for all samples. Sample thickness was checked with an Alpha-step 500 stylus profilometer and found to range between 2.5 and $8.5 \mu \mathrm{m}$. These relatively large thicknesses were necessary to avoid complete shunting of the cells by the nanotubes. CNTbased devices have been fabricated with $V_{\mathrm{oc}}=0.65 \mathrm{~V}, J_{\mathrm{sc}}=$ $0.49 \mu \mathrm{A} / \mathrm{cm}^{2}$, fill factor $=0.35$, and efficiency $=1.35 \times 10^{-4} \%$ [30]. Work is underway to fabricate and test thinner samples and to verify the effectiveness of the alignment.

\section{CONCLUSIONS AND FUTURE WORK}

The PTEBS polythiophene polymer has shown significant photovoltaic response and has been found to be effective for making solar cells. The absorption spectrum and the electrochemical properties (including the bandgap) have been measured. The absorption spectrum can be tuned by adjusting the $\mathrm{pH}$. Solar cells in three different configurations have been produced: titanium dioxide $\left(\mathrm{TiO}_{2}\right)$ bilayer cells, $\mathrm{TiO}_{2}$ bulk heterojunction solar cells, and carbon nanotubes (CNTs) in bulk heterojunctions. The best performance thus far has been achieved with $\mathrm{TiO}_{2}$ bilayer devices. These devices have an open circuit voltage $\left(V_{\text {oc }}\right)$ of $0.84 \mathrm{~V}$, a short circuit current $\left(J_{\mathrm{sc}}\right)$ of $0.15 \mathrm{~mA} / \mathrm{cm}^{2}$, a fill factor $(f f)$ of 0.91 , and an efficiency $(\eta)$ of $0.15 \%$.
PTEBS offers a number of other opportunities for solar cell fabrication. $\mathrm{ZnO}$ nanorods can be grown perpendicularly to a substrate using wet chemistry methods. Nelson et al. fabricated bilayer devices with $\mathrm{ZnO}$ nanorods grown perpendicular to a $\mathrm{ZnO}$ backing layer [33]. Their nanorod devices used a polythiophene polymer and showed power conversion efficiencies $(\eta=0.20 \%)$ five times greater than similar devices made using $\mathrm{ZnO}$ nanoparticles. Our group is fabricating a similar design using PTEBS. The water solubility of the PTEBS may lead to improved $\mathrm{ZnO}$ /polymer bonding.

Other fabrication methods are also well suited to watersoluble polymers. For example, in ionic self-assembly, devices are built up layer-by-layer by alternately dipping the substrate into aqueous cationic and anionic solutions [11]. This allows the fabricator to control the thickness and composition of each nanometer scale layer [34]. In electrochemical self-assembly, well-ordered arrays of quantum dots are built by electrodepositing polymers and other materials into the pores of anodized alumina $[35,36]$. The pores serve as quantum wells modifying the optical and electrical properties of the polymer and potentially resulting in higher device efficiencies. Electrospinning uses large static electric potentials from fine jets of polymer solutions [37, 38]. These jets result in fibers that can be woven into high surface area membranes. Spinning the polymer and the titania simultaneously can result in high interfacial areas. It may also be possible to align nanorods within the fibers. Future experiments will investigate these methods.

\section{REFERENCES}

[1] C. J. Brabec, "Organic photovoltaics: technology and market," Solar Energy Materials and Solar Cells, vol. 83, no. 2-3, pp. 273292, 2004.

[2] A. J. Breeze, Z. Schlesinger, S. A. Carter, and P. J. Brock, "Charge transport in $\mathrm{TiO}_{2} / \mathrm{MEH}-\mathrm{PPV}$ polymer photovoltaics," Physical Review B, vol. 64, no. 12, pp. 12520511252059, 2001.

[3] C. J. Brabec, V. Dyakonov, J. Parisi, and N. S. Sariciftci, Organic Photovoltaics: Concepts and Realization, vol. 60, Springer, New York, NY, USA, 2003.

[4] N. C. Greenham, X. Peng, and A. P. Alivisatos, "A CdSe nanocrystal/MEH-PPV polymer composite photovoltaic ," in Proceedings of Future Generation Photovoltaic Technologies: First NREL Conference, p. 295, Denver, Colo, USA, 1997.

[5] J. Nelson, "Organic photovoltaic films," Materials Today, vol. 5, no. 5, pp. 20-27, 2002.

[6] W. U. Huynh, X. Peng, and A. P. Alivisatos, "CdSe nanocrystal rods/poly(3-hexylthiophene) composite photovoltaic devices," Advanced Materials, vol. 11, no. 11, pp. 923-927, 1999.

[7] Q. Qiao and J. T. McLeskey Jr., "Water-soluble polythiophene/nanocrystalline $\mathrm{TiO}_{2}$ solar cells," Applied Physics Letters, vol. 86, no. 15, Article ID 153501, 3 pages, 2005.

[8] W. J. E. Beek, M. M. Wienk, and R. A. J. Janssen, "Efficient hybrid solar cells from zinc oxide nanoparticles and a conjugated polymer," Advanced Materials, vol. 16, no. 12, pp. 1009-1013, 2004.

[9] A. C. Arango, S. A. Carter, and P. J. Brock, "Charge transfer in photovoltaics consisting of interpenetrating networks of conjugated polymer and $\mathrm{TiO}_{2}$ nanoparticles," Applied Physics Letters, vol. 74, no. 12, pp. 1698-1700, 1999. 
[10] N. C. Greenham, X. Peng, and A. P. Alivisatos, "Charge separation and transport in conjugated-polymer/semiconductornanocrystal composites studied by photoluminescence quenching and photoconductivity," Physical Review B, vol. 54, no. 24 , pp. $17628-17637,1996$.

[11] T. Piok, R. Schroeder, C. Brands, J. R. Heflin, G. Leising, and W. Graupner, "Photocarrier generation quantum yield for ionically self-assembled monolayers," Synthetic Metals, vol. 121, no. 1-3, pp. 1589-1590, 2001.

[12] E. Kymakis and G. A. J. Amaratunga, "Photovoltaic cells based on dye-sensitisation of single-wall carbon nanotubes in a polymer matrix," Solar Energy Materials and Solar Cells, vol. 80, no. 4, pp. 465-472, 2003.

[13] S. B. Lee, T. Katayama, H. Kajii, H. Araki, and K. Yoshino, "Electrical and optical properties of conducting polymer- $\mathrm{C}_{60}$ carbon nanotube system," Synthetic Metals, vol. 121, no. 1-3, pp. 1591-1592, 2001.

[14] C. Y. Kwong, A. B. Djurišić, P. C. Chui, K. W. Cheng, and W. K. Chan, "Influence of solvent on film morphology and device performance of poly(3-hexylthiophene): $\mathrm{TiO}_{2}$ nanocomposite solar cells," Chemical Physics Letters, vol. 384, no. 4-6, pp. 372$375,2004$.

[15] K. E. Strawhecker, S. K. Kumar, J. F. Douglas, and A. Karim, "The critical role of solvent evaporation on the roughness of spin-cast polymer films," Macromolecules, vol. 34, no. 14, pp. 4669-4672, 2001.

[16] F. Tran-Van, M. Carrier, and C. Chevrot, "Sulfonated polythiophene and poly(3,4-ethylenedioxythiophene) derivatives with cations exchange properties," Synthetic Metals, vol. 142, no. 1-3, pp. 251-258, 2004.

[17] American Dye Source Water Soluble Thiophene Polymer, http://www.adsdyes.com/products/pdf/polythiophene/AD S2000P.pdf

[18] Q. Qiao, J. Beck, and J. T. McLeskey Jr., "Photovoltaic devices from self-doped polymers," in Organic Photovoltaics VI, vol. 5938 of Proceedings of SPIE - The International Society for Optical Engineering, pp. 1-9, San Diego, Calif, USA, August 2005.

[19] A. O. Patil, Y. Ikenoue, N. Basescu, et al., "Self-doped conducting polymers," Synthetic Metals, vol. 20, no. 2, pp. 151-159, 1987.

[20] Y. Ikenoue, H. Tomozawa, Y. Saida, M. Kira, and H. Yashima, "Evaluation of electrochromic fast-switching behavior of selfdoped conducting polymer," Synthetic Metals, vol. 40, no. 3, pp. 333-340, 1991.

[21] Q. Qiao, J. Beck, and J. T. Mcleskey Jr., "Optimization of photovoltaic devices from layered PTEBS and nanocrystalline $\mathrm{TiO}_{2}$," Meeting Abstracts MA, vol. 2005-02, pp. 1643-1643, 2005.

[22] I. D. Parker, "Carrier tunneling and device characteristics in polymer light-emitting diodes," Journal of Applied Physics, vol. 75, no. 3, pp. 1656-1666, 1994.

[23] J. Birgerson, M. Keil, A. W. D. Van Der Gon, X. Crispin, M. Lögdlund, and W. R. Salaneck, "A photoelectron spectroscopy study of ethylenedioxythiophene adsorption on polycrystalline gold surfaces," in Proceedings of the Materials Research Society Symposium, vol. 660, pp. JJ5.29.1-JJ5.29.6, San Francisco, Calif, USA, April 2001.

[24] A. Andersson, N. Johansson, P. Bröms, N. Yu, D. Lupo, and W. R. Salaneck, "Fluorine tin oxide as an alternate to indium tin oxide in polymer LEDs," Advanced Materials, vol. 10, no. 11, pp. 859-863, 1998.
[25] Q. Qiao, L. Su, J. Beck, and J. T. McLeskey Jr., "Characteristics of water-soluble polythiophene: $\mathrm{TiO}_{2}$ composite and its application in photovoltaics," Journal of Applied Physics, vol. 98, no. 9, Article ID 094906, 1-7, 2005.

[26] J. S. Salafsky, "Exciton dissociation, charge transport, and recombination in ultrathin, conjugated polymer- $\mathrm{TiO}_{2}$ nanocrystal intermixed composites," Physical Review B, vol. 59, no. 16, pp. 10885-10894, 1999.

[27] F. Tang, T. Uchikoshi, T. S. Suzuki, and Y. Sakka, "Alignment of $\mathrm{TiO}_{2}$ particles by electrophoretic deposition in a high magnetic field," Materials Research Bulletin, vol. 39, no. 14-15, pp. 2155-2161, 2004.

[28] C. Y. Kwong, W. C. H. Choy, A. B. Djurisic, P. C. Chui, K. W. Cheng, and W. K. Chan, "Poly(3-hexylthiophene): $\mathrm{TiO}_{2}$ nanocomposites for solar cell applications," Nanotechnology, vol. 15, no. 9, pp. 1156-1161, 2004.

[29] E. Kymakis, I. Alexandrou, and G. A. J. Amaratunga, "High open-circuit voltage photovoltaic devices from carbonnanotube-polymer composites," Journal of Applied Physics, vol. 93, no. 3, pp. 1764-1768, 2003.

[30] J. A. Rud, L. S. Lovell, J. W. Senn, Q. Qiao, and J. T. Mcleskey Jr., "Water soluble polymer/carbon nanotube bulk heterojunction solar cells," Journal of Materials Science, vol. 40, no. 6, pp. 1455-1458, 2005.

[31] Sigma-Aldrich 519308 Carbon nanotube, single-walled, April 2004, https://www.sigmaaldrich.com.

[32] S. Banda, Z. Ounaies, J. Wilkinson, C. Park, and J. Harrison, "Aligned carbon nanotube-polymer composites: investigating their electrical and physical characteristics," in Smart Structures and Materials 2004: Active Materials: Behavior and Mechanics, vol. 5387 of Proceedings of SPIE - The International Society for Optical Engineering, pp. 27-36, San Diego, Calif, USA, March 2004.

[33] J. Nelson, P. Ravirajana, A. M. Peirób, M. Mohra, J. R. Durrant, and D. D. C. Bradley, "Optimising hybrid polymer/metal oxide solar cells," in The 17th Workshop on Quantum Solar Energy Conversion, Rauris, Austria, March 2005.

[34] R. Schroeder, J. R. Heflin, H. Wang, H. W. Gibson, and W. Graupner, "Control of excited state dynamics in ionically selfassembled monolayers of conjugated molecules," Synthetic Metals, vol. 121, no. 1-3, pp. 1521-1524, 2001.

[35] L. Menon, "Synthesis of nanowires using porous alumina," in Quantum Dots and Nanowires, S. Bandyopadhyay and H. S. Nalwa, Eds., American Scientific, Stevenson Ranch, Calif, USA, 2003.

[36] S. Bandyopadhyay and A. E. Miller, "Electrochemically selfassembled ordered nanostructure arrays: quantum dots, dashes, and wires," in Handbook of Advanced Electronic and Photonic Materials and Devices, H. S. Nalwa, Ed., vol. 6, Academic Press, New York, NY, USA, 2001.

[37] C. Drew, X. Liu, D. Ziegler, et al., "Metal oxide-coated polymer nanofibers," Nano Letters, vol. 3, no. 2, pp. 143-147, 2003.

[38] C. Drew, X. Wang, K. Senecal, et al., "Electrospun photovoltaic cells," Journal of Macromolecular Science, vol. 39A, no. 10, pp. 1085-1094, 2002. 


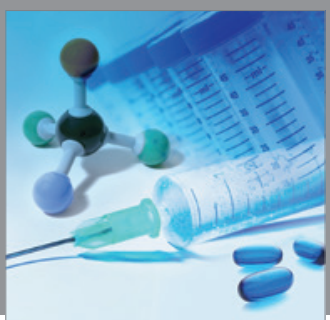

International Journal of

Medicinal Chemistry

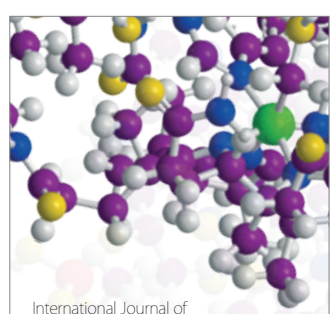

Carbohydrate Chemistry

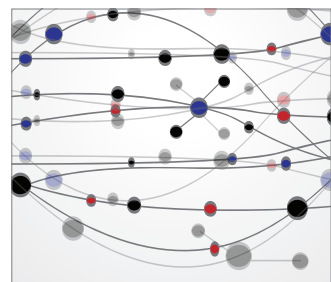

The Scientific World Journal
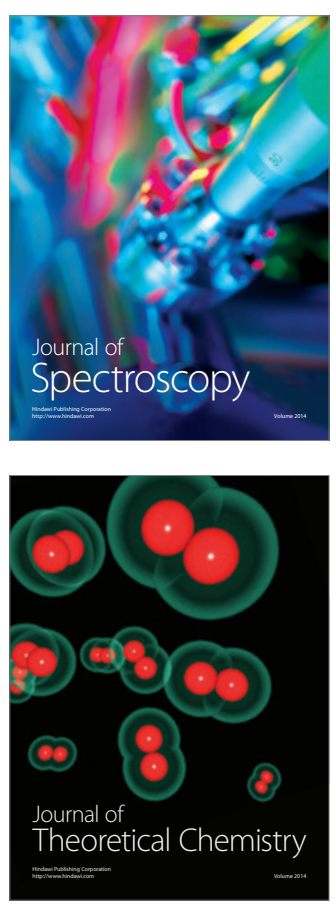
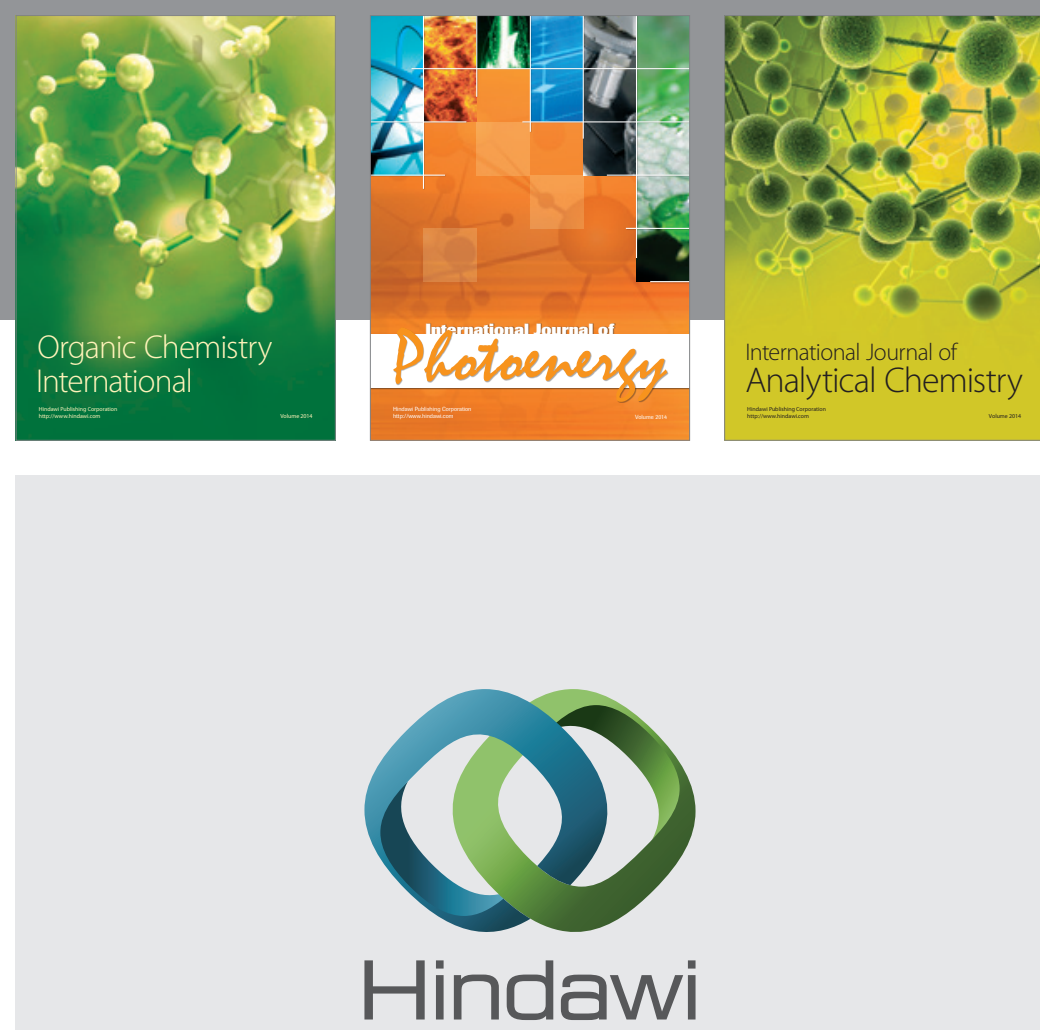

Submit your manuscripts at

http://www.hindawi.com
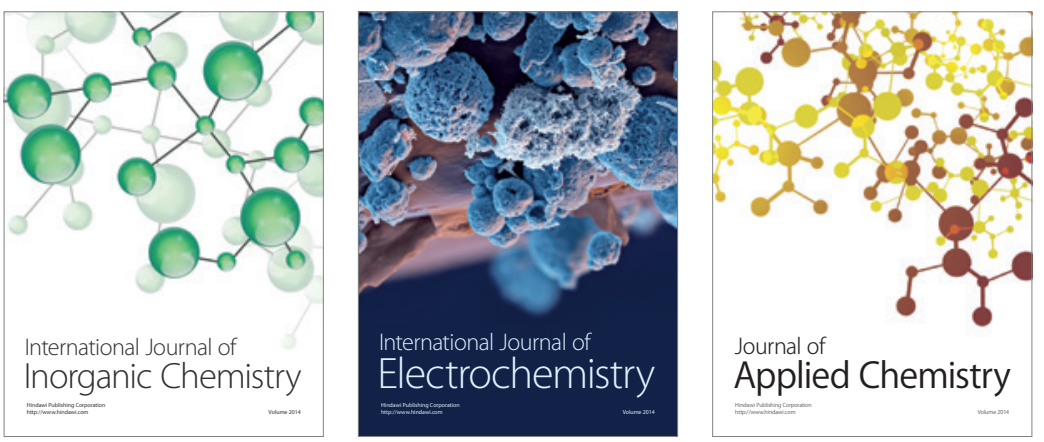

Journal of

Applied Chemistry
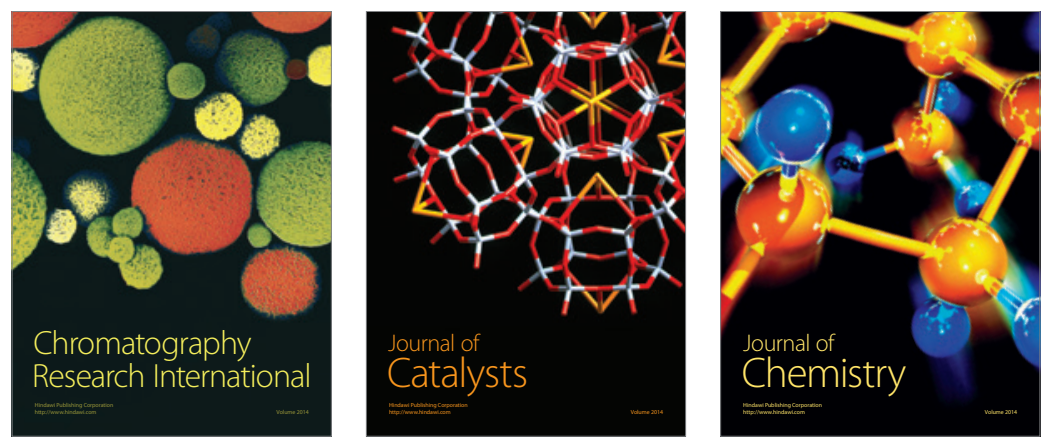
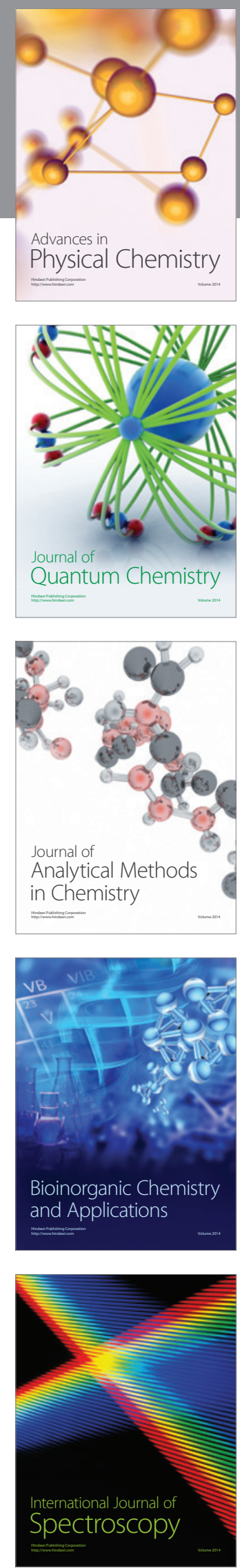